Volume 1 Issue 2

December 2016

\title{
Irish College of Paramedics News
}

\section{Recommended Citation}

Irish College of Paramedics News. Irish Journal of Paramedicine. 2016 Dec; 1(2)

This is an Open Access article distributed under the terms of the Creative Commons Attribution-Non-Commercial-ShareAlike 4.0 International (http://creativecommons.org/licenses/by-nc-sa/4.0/), which permits use, distribution, and reproduction in any medium, provided the original work and any attributes thereof are properly cited, are distributed under the same licence, and that the work is not used for commercial purposes.

Follow the Irish Journal of Paramedicine online at www.irishparamedicine.com, on Twitter (@irishjparamed) and on Facebook. 


\section{Irish College of Paramedics}

"The Professional Body for Irish Pre-hospital Emergency Care Practitioners"

\section{VIOLENCE AGAINST PARAMEDICS OUESTIONNAIRE}

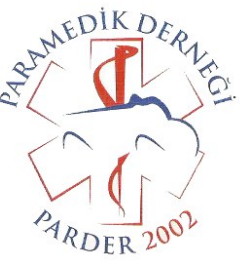

Irish College of Paramedics

"The Professional Body for Irish Pre-hospital Emergency Care Practitioners"

Dr. Shane Knox, President of the Irish College of Paramedics, has been invited to speak to the members of the Turkish Paramedic Association at the 4th International Paramedic Congress and Ambulance Rally taking place in Bodrum, Turkey from the 8-11th December this year.

Shane will be speaking about his research into Continuous Professional Competency and will be meeting with the Executive of the TPA to discuss further collaboration between ICoP and the TPA. Strengthening the ties between $\mathrm{ICoP}$ and paramedic associations worldwide is a priority for the Executive Committee in the coming months. conducting important research into violence against ambulance personnel, and is seeking responses to a multiuniversity, international research survey. Violence against ambulance personnel is a growing problem.

Your input is needed on a multi-university, international research survey to examine violence against ambulance personnel. All ambulance personnel are encouraged to participate. The purpose of the survey is to obtain the information needed for the design of interventions (including training programs, policies and procedures) to reduce and prevent violence against ambulance personnel around the world.

If you'd like, you can visit the survey here: http:// www.vaprp.org. It will take about 15-20 minutes of your time. We hope you will support these efforts to improve the safety of ambulance personnel worldwide. As a token of appreciation for your time, all participants who chose to participate will be entered in to a drawing for iPads.

The ICoP Member Services Guide 2016 outlines the many benefits of membership of the Irish College of Paramedics. Also contained in this guide are details of many exclusive member-only discounts, on medical supplies, textbooks, car, home and travel insurance, $\mathrm{CPC}$ activities, conferences, training courses, instructor courses and

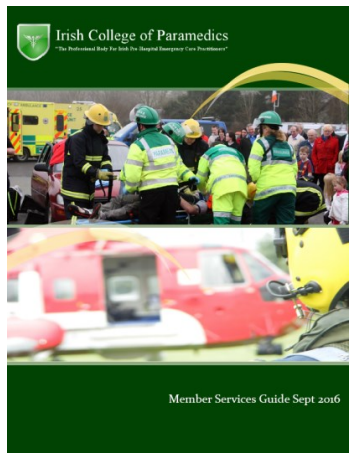
more.

All this for only 10EUR per year! This is fantastic value, as many of the discounts we have secured for our members are worth several times the membership fee!

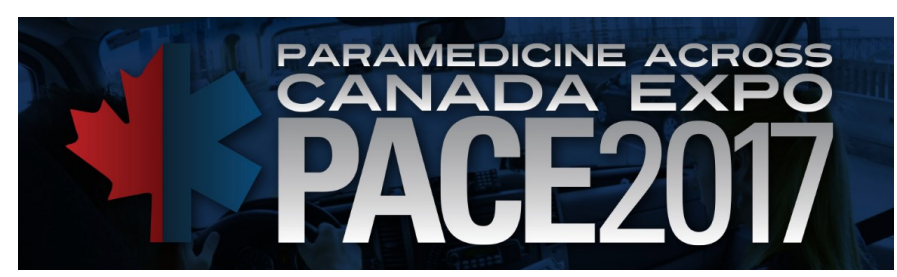

Alan Batt, ICoP Executive Member (Member Services Officer) and Editor of the Irish Journal of Paramedicine, has been invited to speak at the upcoming Paramedic Association of Canada (PAC) "Paramedicine Across Canada Expo" (PACE) to be held in Quebec City, in August 2017.

The Paramedicine Across Canada Expo is designed to bring together front-line paramedics from all practice settings to learn and network with each other. Regardless of location, background, or experience, the various tracks that this conference offers (clinical, education, specialty, as well as mental health and wellness) ensure there is something of interest for everyone.

This is an Open Access article distributed under the terms of the Creative Commons Attribution-Non-Commercial-ShareAlike 4.0 International (http:// creativecommons.org/licenses/by-nc-sa/4.0/), which permits use, distribution, and reproduction in any medium, provided the original work and any attributes thereof are properly cited, are distributed under the same licence, and that the work is not used for commercial purposes. Content copyright remains with the authors, who grant the IJP a licence to reuse and distribute. 